\title{
Evaluation of Paired Diffractive Bifocal Iols (Acri.Twin) In Indian Patients of Cataract: Research Paper
}

\author{
Dr. Amit Sharma \\ I. Introduction
}

Intraocular lens implantation is a fundamental development in cataract surgery. A conventional monofocal lens does not provide the full visual acuity over the whole range from distance to near. A more reliable means of achieving accommodation is with a multifocal IOL, which provides functional vision over a range of distances from far to near. Currently available multifocal lenses are based on two different principles: the diffractive and refractive.

A diffractive lens combines refractive and diffractive optical principles to achieve simultaneous vision. It has an anterior spheric surface and multiple diffractions on its posterior surface. This diffractive portion uses discrete zone steps to control the wave property of light and produces two primary powers used for distance and near focus.

The newly developed Acri.Twin bifocal intraocular lenses are characterized by an asymmetrical light distribution. The dominant eye is implanted with a bifocal lens with a light distribution of $70 \%$ for the far focus and $30 \%$ for the near focus. The accompanying eye will receive an intraocular lens with a light distribution of $70 \%$ for the near focus and $30 \%$ for the far focus. As a result a considerable improvement of the contrast can be achieved.

\section{Materials and Methods}

This prospective study was conducted at department of ophthalmology, Sir Ganga Ram Hospital, New Delhi, India from november 2004 to december 2006.

The total number of cases were 20 with both eyes Acri.Twin lens implantation

\section{Exclusion Criteria:}

1. Pre-existing ocular pathology apart from cataract.

2. High postoperative visual acuity expectation or occupational requirements of the patients.

3. Astigmatism of more than $1.0 \mathrm{D}$.

4. Intraoperative complications that could compromise lens centration.

\section{Surgery:}

Informed and written consent was taken. Unaided and best corrected visual acuity was recorded. Keratometry was done with Bausch and Lomb keratometer. The SRK-II (Sanders Retzlaff Kraff) regression formulae was used to calculate the power of IOL to be implanted. All surgeries were performed by phacoemulsification under topical anaesthesia with $2 \%$ lignocaine hydrochloride Under all aseptic precautions. An Acri.Twin 737 (70\% for far, 30\% for near) lens was placed in the first eye. The second eye surgery was done within 3 months with placement of Acri.Twin 733(70\% for near, 30\% for far) lens.

\section{Follow Up and Assessment:}

Patients were evaluated on the first postoperative day, day 7, day 14, 1 month and 3 month. The parameters evaluated were

\section{Visual acuity}

Distance visual acuity measured with the snellens distance visual acuity chart and near acuity was tested with th e help of near test type

\section{Contrast sensitivity}

Contrast sensitivity was tested with the help of Pelli Robson contrast sensitivity chart.

3. patient's satisfaction

To determine patient's satisfaction, patients were asked to complete a questionnaire on their level of satisfaction with vision during activities at near, intermediate and distance.

\section{Set of questions}

Reading a newspaper or book.Fixing something precisely e.g. sewing, knitting. 


\section{Observation and Results:}

Measures were taken in each case at 6 weeks.

1. Uncorrected Distance visual acuity

\begin{tabular}{|l|l|l|l|}
\hline Visual acuity & First Eye (Acri.Twin737D) & Second Eye (Acri.Twin733D) & Binocular \\
\hline $6 / 6$ & 3 & 3 & 6 \\
\hline $6 / 9$ & 10 & 9 & 12 \\
\hline $6 / 12$ & 6 & 7 & 2 \\
\hline $6 / 18$ & 1 & 1 & 0 \\
\hline $6 / 24$ & 0 & 0 & 0 \\
\hline$<6 / 36$ & 0 & 0 & 0 \\
\hline
\end{tabular}

With distance dominant 737D Acri.Twin implanted in the first eye, $65 \%$ of the total patients had visual acuity better than $6 / 9$. Out of these $23 \%$ were $6 / 6$. With near dominant $733 \mathrm{D}, 60 \%$ had visual acuity better than $6 / 9$. Out of these $25 \%$ were $6 / 6$. Binocularly, $90 \%$ had visual acuity better than $6 / 9$. Out of these $33 \%$ were $6 / 6$.

2. Best corrected distance visual acuity

\begin{tabular}{|l|l|l|l|}
\hline Visual acuity & First eye (Acri.Twin737D) & $\begin{array}{l}\text { Second eye } \\
\text { (Acri.Twin733D) }\end{array}$ & Binocular \\
\hline $6 / 6$ & 14 & 13 & 18 \\
\hline $6 / 9$ & 6 & 7 & 2 \\
\hline $6 / 12$ & 0 & 0 & 0 \\
\hline $6 / 18$ & 0 & 0 & 0 \\
\hline $6 / 24$ & 0 & 0 & 0 \\
\hline
\end{tabular}

$100 \%$ of patients with distance dominant Acri.Twin (737D) had visual acuity better than $6 / 9$ with refractive correction of not more than $\pm 1 \mathrm{D}$ sphere/cylinder. Out of these $70 \%$ patients were $6 / 6.100 \%$ of patients with near dominant Acri.Twin (733D) had visual acuity better than $6 / 9$. Out of these $65 \%$ were $6 / 6$. Binocularly all patients were better than $6 / 9$. Out of these $90 \%$ were $6 / 6$.

3. Uncorrected near visual acuity

\begin{tabular}{|l|l|l|l|}
\hline Near vision & $\begin{array}{l}\text { First Eye } \\
\text { (Acri.Twin737D) }\end{array}$ & $\begin{array}{l}\text { Second Eye } \\
\text { (Acri.Twin733D) }\end{array}$ & Binocular \\
\hline N6 & 3 & 12 & 15 \\
\hline N8 & 13 & 8 & 5 \\
\hline N10 & 3 & 0 & 0 \\
\hline N12 & 1 & 0 & 0 \\
\hline$<$ N12 & 0 & 0 & 0 \\
\hline & & & \\
\hline
\end{tabular}

With distance dominant Acri.Twin 737D implanted in the first eye, $80 \%$ of the total patients had near vision better than N8. $100 \%$ of the patients with near dominant Acri.Twin 733D had near vision better than N8. Out of these $60 \%$ were N6. Binocularly, all patients were better than N8. Out of these $75 \%$ were N6.

4. Corrected near visual acuity

\begin{tabular}{|l|l|l|l|}
\hline Near Vision & First Eye (Acri.Twin737D) & $\begin{array}{l}\text { Second Eye } \\
\text { (Acri.Twin733D) }\end{array}$ & Binocular \\
\hline N4.5 & 0 & 0 & 2 \\
\hline N6 & 17 & 18 & 18 \\
\hline N9 & 3 & 2 & 0 \\
\hline N12 & 0 & 0 & 0 \\
\hline
\end{tabular}

With near correction of not more than $+1 \mathrm{D}$ binocularly all the patients were able to read N6.

With near add $85 \%$ of the patients, implanted with 737D Acri.Twin (distance dominant) were N6. With near addition of not more than $+1 \mathrm{D}, 90 \%$ of the patients implanted with $733 \mathrm{D}$ Acri. Twin (near dominant) were N6.

Normal Values Of Contrast Sensitivity By Pelli Robson Method

\begin{tabular}{|c|c|c|}
\hline $\begin{array}{c}\text { Age } \\
\text { (Years) }\end{array}$ & $\begin{array}{c}\text { Uniocular Contrast Sensitivity at } 1 \mathrm{~m} \\
(\log \text { units })\end{array}$ & $\begin{array}{c}\text { Binocular contrast sensitivity at } 1 \mathrm{~m} \\
(\log \text { units })\end{array}$ \\
\hline $6-19$ & & $1.80-1.95$ \\
\hline Range & $1.65-1.95$ & $1.92+/-0.06$ \\
\hline Mean +/-SD & $1.75+/-0.10$ & $1.95-2.10$ \\
\hline $20-39$ & & $1.97+/-0.07$ \\
\hline Range & $1.65-1.95$ & \\
\hline Mean $+/-$ SD & $1.84+/-0.82$ & $1.80-2.10$ \\
\hline Range & & $1.94+/-0.07$ \\
\hline Mean +/-SD & $1.65-1.95$ & \\
\hline$>/=60$ & $1.76+/-0.12$ & $1.65-1.95$ \\
\hline Range & & $1.90+/-0.11$ \\
\hline Mean $+/-$ SD & $1.50-1.80$ & \\
\hline
\end{tabular}




\begin{tabular}{|l|l|l|l|}
\multicolumn{2}{l}{ Contrast Sensitivity(log units) } \\
\hline Contrast Sensitivity & First Eye (Acri.Twin737D) & $\begin{array}{l}\text { Second Eye } \\
\text { (Acri.Twin733D) }\end{array}$ & Binocular \\
\hline$\geq 1.95$ & 8 & 11 & 15 \\
\hline 1.8 & 6 & 5 & 5 \\
\hline 1.65 & 6 & 4 & 0 \\
\hline$<1.65$ & 0 & 0 & 0 \\
\hline
\end{tabular}

With 737D distance dominant Acri.Twin 70\% of the patients were better than $1.8 \log$ units on the Pelli Robson contrast sensitivity chart. Out of these $57 \%$ were $1.95 \log$ units or above.

With 733D near dominant Acri.Twin 80\% of the total patients were better than $1.8 \log$ units. Out of these $69 \%$ were $1.95 \log$ units or above or above.

Binocularly all the patients were better than $1.8 \log$ units. Out of these $75 \%$ were $1.95 \log$ units or above.

\section{Review of Literature}

Hoffer $^{1}$ in 1982 was the first to hit upon the idea of a multifocal IOL after observing a patient who had $6 / 6$ vision inspite of an IOL that was decentered by more than $50 \%$ of the pupillary area. The credit goes to Dr. John Pierce in 1986, who implanted the 'bulls eye' style of multifocal IOL.

Hansen $^{2}$ et al had promising results with multifocal IOL and actually concluded that this IOL could return a multifocal capacity, that is lost at 40-50 years of age without any more disadvantages than with conventional IOLs.

Steinert ${ }^{3}$ et al reported that significant less correction was required in the multifocal group than in the monofocal group both for distance and near. However, patients in the multifocal group sustained a small loss of contrast sensitivity.

Holladay $^{4}$ et al evaluated the optical performances of several multifocal lenses, using laboratory and photographic studies. They found a two to three fold increase in depth of field for all multifocals, but they also found a 50\% reduction in contrast in the retinal image and a one line drop in the best corrected acuity

Percival and Setty ${ }^{5}$ conducted several clinical trials of multifocal lenses and found better simultaneous distance and near acuity.

Vaquero-Ruano ${ }^{6}$ et al reported a wider depth of focus and significantly better vision without addition in patients with multifocal lenses. The contrast sensitivity results at $96 \%$ and $50 \%$ contrast sensitivity were similar.

Walkow $^{7}$ et al prospectively evaluated a diffractive versus a refractive multifocal IOL and found similar and satisfactory functional results with both, except that near uncorrected vision was significantly better with the diffractive lens.

Herbert Weghaupt ${ }^{8}$ et al showed that pseudoaccommodation and full distance visual acuity was realized with both types of multifocal lenses. At near distances, the $3 \mathrm{M}$ lens provided statistically significant better visual acuity.

Negishi $^{9}$ et al demonstrated that eyes implanted with the five zone refractive multifocal lenses had better near visual acuity than control eyes and compared favorably in other aspects of visual functions.

$\mathbf{J a c o b i}^{\mathbf{1 0}}$ et al developed a new concept of (asymmetric bilateral multifocal IOL implantation) distant dominant multifocal IOL with a light distribution of $70 \%$ for the far focus and $30 \%$ for the near focus is implanted in one eye and a near dominant multifocal IOL with light distribution of $30 \%$ for distance and $70 \%$ for near focus is implanted in the fellow eye.

They found that the effect was additive and that the asymmetric model may be associated with improved contrast sensitivity compared with conventional multifocal IOLs.

Stefen Pieh ${ }^{11}$ et al found new foldable diffractive bifocal IOLs show promising results. Dr Pieh found the foldable Acri.Tec 737 and 733 lenses are easy to implant through a $3.2 \mathrm{~mm}$ clear cornea incision. Near and Far vision results were both very good. Binocular results were better than monocular results in all cases, although monocular values often came close.

Weghaupt $\mathbf{H}^{12}$ et al determine depth of focus and visual quality after implantation of a diffractive intraocular lens (3M 825x) and a refractive IOL (AMO Array SSM 26NB) and found that pseudoaccommodation and full distance visual acuity were realized with both types of multifocal lenses though at near distances, the diffractive lens provided statistically significantly better visual acuity.

Jacobi $\mathbf{F} \mathbf{K}^{13}$ et al evaluated visual results after bilateral implantation of multifocal intraocular lenses with asymmetric light distribution for the far and near focus and concluded that bilateral implantation of asymmetric diffractive IOLs is an effective alternative for restoring simultaneous distance and near vision with a potential for improved contrast sensitivity compared with conventional multifocal IOLs.

A comparative clinical study by Alio $\mathbf{J} \mathbf{L}^{14}$ et al, who evaluated near visual performance after implantation of a pseudoccommodating IOL (Crystalens AT-45, eyeonics) or a multifocal IOL (refractive 
model, AMO Array; diffractive model, Acritec Twinset) after lens surgery. They concluded that implantation of multifocal and pseudoaccommodating IOLs provides adequate near vision restoration. The twinset IOL provided faster recovery of near vision than the other 2 IOLs. The Crystalens IOL provided less postoperative visual phenomena with favorable near vision. The Array IOL achieved the most comfortable distance and near vision.

Mester $\mathbf{U}^{15}$ et al compared a multifocal intraocular lens (MIOL) with diffractive and aspherical optical design and asymmetrical light distribution (Acti.Twin, Acri.Tec) was compared to the standard MIOL, the Array SA40. A significant difference was observed between the two MIOL in improved near visual acuity of the Acri.Twin MIOL ( 0.8 vs 0.4 ). Concerning contrast sensitivity both MIOL were significantly inferior to data published for an aspherical monofocal IOL.

Monocular and binocular depth of focus with different multifocal IOLs were evaluated by Schmidinger $\mathbf{G}^{\mathbf{1 6}}$ et al. In this comparative interventional study, binocular implantation of multifocal IOLs was performed in 3 groups. In the first group, 26 eyes of 13 patients received asymmetric Acri.Twin (Acri,Tec) IOLs, a near-weighted 733D in one eye and a distance weighted $737 \mathrm{D}$ in the fellow eye. In the second eye, 26 eyes of 13 patients received a diffractive 811E IOL (Pharmacia). In the third group, 26 eyes of 13 patients received a refractive Array IOL ( AMO). The Acri.Twin group had better distance visual acuity than the Array group $(\mathrm{P}<$ or $=.048)$. Near visual acuity was best in eyes with the near-weighted $733 \mathrm{D}$, followed by 737D and the 811E. Patients with diffractive bifocal IOLs had better results than patients with refractive multifocal IOLs at reading distance $(\mathrm{P}<$ or $=.018)$.

Walkow $\mathbf{L}^{17}$ et al studied the optimal patient satisfaction after implantation of diffractive designed multifocal intraocular lenses in dependence on objective parameters. They found that for diffractive designed multifocal IOLs, emmetropia and a low astigmatism postoperatively are the most important factors for high patient satisfaction.

Schmidinger $\mathbf{G}^{\mathbf{1 8}}$ et al compared contrast sensitivity function in eyes with diffractive bifocal IOLs. They evaluated the image quality of asymmetric Acri.Twin bifocal IOLs (Acri.Tec) by comparing distance and near black-white contrast sensitivity function with that of the pharmacia 811E IOL. 32 eyes of 16 patients were examined after contralateral implantation of one Acri.twin near weighted 733D IOL and 1 Acri.Twin distance weighted 737D IOL. Twenty eyes of 10 patients were examined after binocular Pharmacia 811E IOL implantation. Best corrected distance visual acuity was significantly better in patients with the 737D IOL than in those with 733D or $811 \mathrm{E}$ IOLs. At distance, contrast sensitivity function was better with the 737D IOL, whereas no difference was found between the 733D and 811E IOLs. Binocular contrast sensitivity function at distance revealed statistically significantly better results in the Acri.Twin group. They concluded that asymmetric diffractive bifocal lens system was advantageous in terms of vision quality when implanted binocularly and superior to monocular stronger weighted focus compared with conventional bifocal IOLs.

\section{Bibliography}

[1]. Hoffer K J. Preoperative evaluation of cataractous patients. Surv Ophthalmol 1984 Jul-Aug; 29(1): 55-69.

[2]. Hansen T, Corydon L, Kraag S, Thim K. New multifocal intraocular lens design. J Cataract Refract Surg 1990 Jan; 16(1): 38-41.

[3]. Steinert RF, Post CT jr, Brint SF. A prospective, randomized double masked comparison of a zonal progressive multifocal IOl and monofocal IOL. Ophthalmology 1992; 99:853-860.

[4]. Holladay J T, Van Dijk H, Lang A. Optical performance of multifocal IOL. J Cataract Refract Surg. 1990; 16:413-422.

[5]. Percival SPB, Setty SS. Comparative Analysis of three prospective trials of multifocal implants. Eye 1991; 5:712-716.

[6]. Vaquero-Ruano M, Encinas J L, Millan I, Hyos M, Cajigal C. AMOARRAY multifocal v/s monofocal intraocular lenses-Long term follow up. J Cataract Refract Surg 1998; 24:118-123.

[7]. Walkow L, Klemen U M. Patient satisfaction after implantation of diffractive designed multifocal intraocular lenses in dependence on objective parameter. Graefe Arch Clin Exp Ophthalmol 2001 Sept; 239(9): 683-7.

[8]. Weghaupt H, Pieh S, Skorpik C. Comparison of pseudoaccommodation and visual quality between a diffractive and refractive multifocal intraocular lens. J Cataract Refract Surg 1998; 24:663-665.

[9]. Negishi K, Nagamoto T, Hara E, Kurosaka D, Miyajima H B. Clinical evaluation of a five zone multifocal intraocular lens. J Cataract Refract Surg 1996 Jan-Feb; 22(1):110-5.

[10]. Jacobi P C, Dietlein T S, Luke C, Jacobi F K. Multifocal intraocular lens implantation in presbyopic patients with unilateral cataract. Ophthalmology 2002 April; 109(4): 680-684.

[11]. Pieh S, Weghaupt H, Skorpik C. Contrast sensitivity and glare disability with diffractive and refractive multifocal IOL. J Cataract and Refract Surgery 1998; 24:659-662.

[12]. Weghaupt H, Pieh S, Skorpik C; Comparison of pseudoaccommodation and visual quality between a diffractive and refractive multifocal intraocular lens. J Cataract Refract Surg. 1998 May;24(5):663-5

[13]. Jacobi F K, Kammann J, Jacobi K W, Grosskopf U, Walden K; Bilateral implantation of asymmetric diffractive multifocal intraocular lenses. Arch Ophthalmol, 1999 Jan;117(1):17-23

[14]. Alio J L, Tavolato M, De la Hoz F, Claramonte P, Rodriguez-Prats J L, Galal A; Near vision restoration with refractive lens exchange and Pseudoaccommodating and multifocal refractive and diffractive intraocular lenses: comparative clinical study. J Cataract refract Surg. 2004 Dec;30(12):2494-503 
[15]. Mester U, Dillinger P, Anterist N, Kaymak H; Functional results with two multifocal intraocular lenses (MIOL) Array SA 40 versus Acri.Twin.Ophthalmologe.2005 Nov; 102(11):1051-6

[16]. Schmidinger G, Geotzenauer W, Hahsle B, Klemen UM, Skorpik C, Pieh S; Depth of focus in eyes with diffractive bifocal and refractive multifocal intraocular lenses. J Cataract Refract Surg. 2006 Oct;32 (10):1650-6

[17]. Walkow L, Klemen U M; Patient satisfaction after implantation of diffractive designed multifocal intraocular lenses in dependence on objective parameters. Graefes Arch Clin Exp Ophthalmol 2001 Sep; 239 (9) : 683-7

[18]. Schmidinger G, Simader C, Dejaco-Ruhswurm I, Skorpik C, Pieh S; Contrast sensitivity function in eyes with diffractive bifocal intraocular lenses. J Cataract Refract Surg. 2005 Nov; 31(11):2076-83 